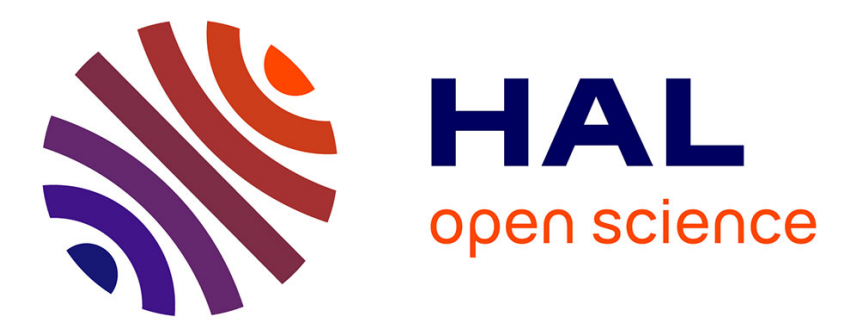

\title{
A Portable Impedance Detector of Interdigitated Array Microelectrode for Rapid Detection of Avian Influenza Virus
}

Xiaohong Wang, Zhuo Zhao, Yuhe Wang, Jianhan Lin

\section{- To cite this version:}

Xiaohong Wang, Zhuo Zhao, Yuhe Wang, Jianhan Lin. A Portable Impedance Detector of Interdigitated Array Microelectrode for Rapid Detection of Avian Influenza Virus. 8th International Conference on Computer and Computing Technologies in Agriculture (CCTA), Sep 2014, Beijing, China. pp.247-256, 10.1007/978-3-319-19620-6_31 . hal-01420240

\author{
HAL Id: hal-01420240 \\ https://hal.inria.fr/hal-01420240
}

Submitted on 20 Dec 2016

HAL is a multi-disciplinary open access archive for the deposit and dissemination of scientific research documents, whether they are published or not. The documents may come from teaching and research institutions in France or abroad, or from public or private research centers.
L'archive ouverte pluridisciplinaire HAL, est destinée au dépôt et à la diffusion de documents scientifiques de niveau recherche, publiés ou non, émanant des établissements d'enseignement et de recherche français ou étrangers, des laboratoires publics ou privés.

\section{(c)(1)}

Distributed under a Creative Commons Attribution| 4.0 International License 


\title{
A Portable Impedance Detector of Interdigitated Array Microelectrode for Rapid Detection of Avian Influenza Virus
}

\author{
Xiaohong Wang ${ }^{1, \mathrm{a}}$, Zhuo Zhao ${ }^{2, \mathrm{~b}}$, Yuhe Wang ${ }^{2, \mathrm{c}}$, Jianhan $\operatorname{Lin}^{1, \mathrm{~d} *}$ \\ ${ }^{1}$ MOA Key Laboratory of Agricultural information acquisition technology (Beijing), China \\ Agricultural University, Beijing 100083,China \\ ${ }^{2}$ Modern Precision Agriculture System Integration Research Key Laboratory of Ministry of \\ Education, China Agricultural University, Beijing 100083, China \\ awxh16@163.com.cn, ${ }^{\mathrm{b}} 1992$ zhaozhuo@gmail.com, ${ }^{\mathrm{c}}$ cauyuhe@gmail.com, \\ jianhan@cau.edu.cn \\ Corresponding author: Jianhan Lin, Associate Professor, China Agricultural University, \\ Telephone:+86-10-62737599. Email: jianhan@cau.edu.cn
}

\begin{abstract}
Impedance biosensors are featured with fast detection, easy operation and low-cost, and have been reported in the detection of avian influenza viruses, foodborne pathogens and pesticide residues. Based on our previous research on impedance biosensors for rapid detection of avian influenza virus, a portable impedance detector was redesigned using an S3C2440AL ARM9 microprocessor and an improved AD5933 impedance converter to meet the higher requirements on frequency and magnitude in impedance measurement from the new interdigitated array microelectrodes, which were redesigned for reducing the cost and improving the produce quality. The impedance measurement range is $50 \Omega-1 \mathrm{M} \Omega$ and the frequency response range is $100 \mathrm{~Hz}-$ $100 \mathrm{kHz}$. Compared to commercial E4980A precision LCR meter on the measurements of solid-state resistor, solid-state equivalent circuit of the electrode and avian influenza virus test, this impedance detector showed a relative error of less than $5 \%$ at the characteristic frequency of $100 \mathrm{~Hz}$ and a standard deviation of less than $5 \%$ in parallel tests. Besides, a linear relationship between impedance change $\Delta \mathrm{Z}$ and the concentration of avian influenza virus ranging from $2^{-1} \mathrm{HAU} / 50 \mu \mathrm{l}$ to $2^{4} \mathrm{HAU} / 50 \mu \mathrm{l}$ was found.
\end{abstract}

Keywords: impedance analysis, biosensor, interdigitated array microelectrode, avian influenza detection

\section{Introduction}

Avian influenza (AI) is an infectious disease of birds caused by influenza A virus. According to WHO statistics, animals in 62 countries and people in 15 countries have been infected by AI H5N1 virus since 2003, and the mortality rate of human is nearly $60 \%$ [1]. Highly pathogenic AI H5N1 has caused huge economic losses and has become a serious threat to public health and safety. 
Rapid screening of suspected cases is quite critical to preventing and controlling the spread of AI H5N1 virus. Conventional methods for detection of H5N1 virus mainly include viral isolation culture and RT-PCR. However, these methods are not suitable for in-field screening of AI H5N1 due to their time-consuming procedures or complex sample pretreatment and requirement on specialized facilities. As an alternative, impedance biosensors have shown their potentials to offer a rapid, simple and sensitive detection [2] and have been reported in literatures for detection of biological and chemical targets, including foodborne pathogens [3-6], pesticide residues [7-8] and AI virus [9-10]. Interdigitated array (IDA) microelectrodes are often used in the fields of electrochemical analysis [11-13] with advantages of high sensitivity, low detection limit and high signal to noise ratio [14-17] and has been reported in the studies on detection of AI virus and foodborne pathogens [18-23].

In our previous studies, an impedance biosensor was developed with advantages over conventional methods in detection of avian influenza, such as high specificity, high sensitivity and fast detection [9-10]. This impedance biosensor used the antibodies against AI virus immobilized onto the IDA microelectrode to capture the viruses and this resulted in an impedance increase of the electrode because the viruses blocked the electron transfer between the electrode and the electroactive probes. The impedance change was measured using a commercial impedance analyzer and analyzed to determine the concentration or presence of AI viruses. Meanwhile, an impedance detector based on an 89C51 single-chip microprocessor was developed for in-field measurement of impedance change of the IDA microelectrode with the measuring frequency of $10 \mathrm{kHz}$ and the impedance measurement resolution of $1 \mathrm{k} \Omega$ [24]. However, the IDA electrode was recently redesigned for the purpose of reducing the cost and improving the quality. The characteristic response frequency was found to shift to $50-100 \mathrm{~Hz}$ from original $1-10 \mathrm{kHz}$ and the impedance values of the electrode were measured with smaller lower-limit-amplitude of $\sim 100 \Omega$ from original $\sim 1 \mathrm{k} \Omega$. Both the characteristic response frequency and the lower-limit-amplitude were beyond the range of the previously-developed impedance detector. Therefore, this study intended to redesign and develop a portable impedance detector to meet the higher requirements on frequency and amplitude in impedance measurement from the newly-redesigned IDA microelectrode and evaluated using solid-state circuits and AI virus.

\section{Development of Impedance Detector}

\subsection{Hardware Redesign}

Since ARM microprocessors generally have obvious advantages over 51 single-chip microprocessors, such as faster processing speed and more peripheral resources, the impedance detector was redesigned using an S3C2440AL ARM9 microprocessor instead of original 89C51 single-chip microcontroller and an improved AD5933 impedance converter with an external clock and a signal conditioning circuit. As shown in Fig.1, the hardware includes: (1) an impedance measurement module to 
measure the impedance amplitude and phase angle of the electrode, (2) a powersupply module using an AMS1117-3.3 low dropout linear regulator to provide with accurate 3.3 voltage from 5 VDC power adaptor, (3) a data storage module using a K9F2G08UXA flash memory to save the testing data, (4) a serial communication module using an SP3232EEN chip for program debugging, and (5) a USB communication module to send the testing data to computer, and (6) a WXCAT35TG3 TFT-LCD touch screen to display the data and operate the detector.

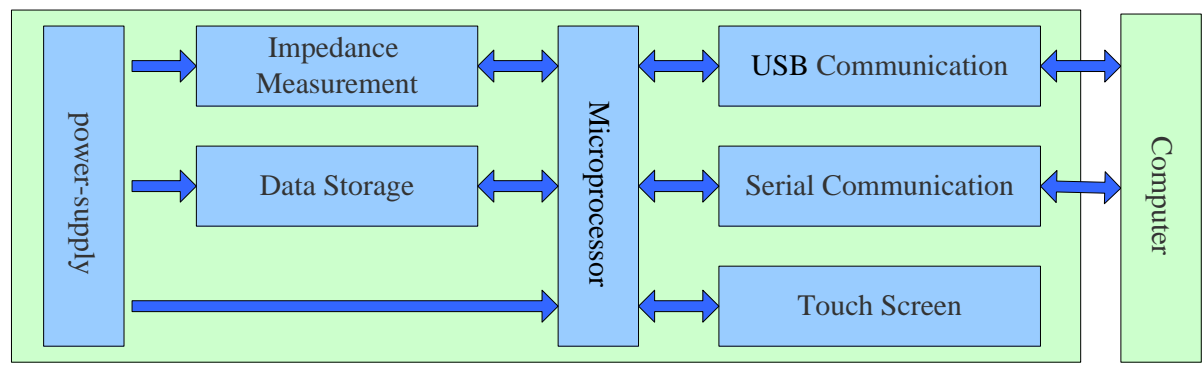

Fig.1. Schematic diagram of the hardware structure of the impedance detector

Impedance measurement is vital for the development of the impedance detector. The impedance measurement module was redesigned based on our previous prototype with an AD5933 impedance converter, a high-pass filter, a voltage follower, a current-voltage converter and an impedance measuring range adjustor.

The AD5933 impedance converter obtained from Analog Device used Discrete Fourier Transform (DFT) to convert the data collected in the time domain into the frequency domain and obtained the real part $(R)$ and the imaginary part $(I)$, which could be accessed through the $\mathrm{I}^{2} \mathrm{C}$ interface. However, its frequency response range was $1-100 \mathrm{kHz}$, which didn't cover the characteristic frequency of the newly redesigned electrode, and impedance measuring range was $1 \mathrm{k} \Omega-1 \mathrm{M} \Omega$, which didn't cover the impedance amplitude of the electrode for detection of AI virus. Thus, an external clock with a frequency of $125 \mathrm{kHz}$ generated by an internal timer of the microprocessor was employed and provided to the AD5933 converter.

Since the excitation signal with a peak-to-peak voltage of $0.198 \mathrm{~V}$ from AD5933 applied on the electrode had a DC bias of $0.173 \mathrm{~V}$, which didn't match that of the signal receiver in AD5933 with a DC bias of $1.650 \mathrm{~V}$, the electrode might be polarized and the impedance measuring accuracy was greatly affected due to the saturation of analog-digital converter in AD5933. Thus, the excitation signal was sequentially processed by a first order high-pass filter with a cut-off frequency of 1 $\mathrm{Hz}$, a voltage follower using 1/2 AD8606 to make the DC bias of the excitation signal $1.650 \mathrm{~V}$, and a current-voltage converter using 1/2 AD8606 to convert the current passing the electrode into voltage. Besides, an impedance measuring range adjustor using ADG811 was used to automatically adjust the feedback resistor (four optional: $100 \Omega, 1 \mathrm{k} \Omega, 10 \mathrm{k} \Omega$ and $100 \mathrm{k} \Omega$ ) to make the ratio of the feedback resistor to the electrode between 0.1 and 1.0, indicating that the analog-digital converter in AD5933 was working in linear range. 


\subsection{Embedded Software Development}

The embedded software of the impedance detector was developed using Linux $\mathrm{C}$ for driver programming and QT4 for application programming under Linux environment. As shown in Fig.2, the embedded software mainly included three dialog boxes for system setting, impedance measurement and analysis, and data display and storage.

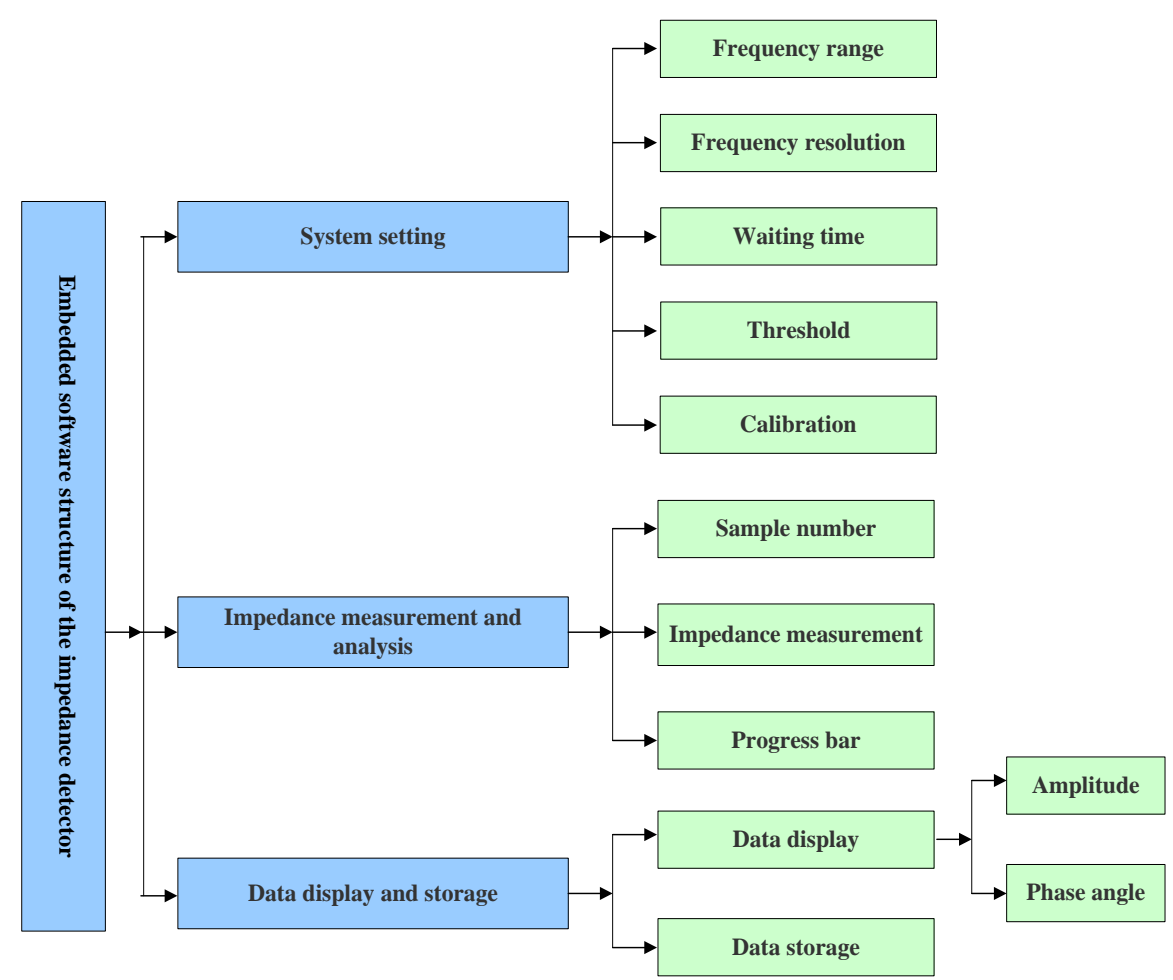

Fig. 2. Schematic diagram of the embedded software structure of the impedance detector

In the dialog box for system setting, system parameters, such as the scanning frequency range and resolution for impedance measurement, the threshold for determining the presence of $\mathrm{AI}$ virus, and the waiting time for AI virus incubation, could be set using QcomboBox and QspinBox classes. Besides, system calibration was achieved with the use of standard resistors.

In the dialog box for impedance measurement and analysis, the number of testing samples was automatically set and increased by one after the sample was done. Also, a progress bar using QprogressBar was used to display the progress of the measurement. As shown in Fig. 3, the impedance data were obtained by the following procedures: (1) initialize AD5933, (2) set the parameters in the dialog box for system setting, (3) collect impedance data including real value $(R)$ and imaginary value $(I)$ and calculate impedance amplitude $(M)$ and phase angle $(A)$, (4) judge data validity, (5) save valid data and repeat seven measurements, (6) bubble sort the seven valid 
impedance data, (7) average the three middle impedance data as the result $\left(M_{A}\right)$ for impedance measurement.

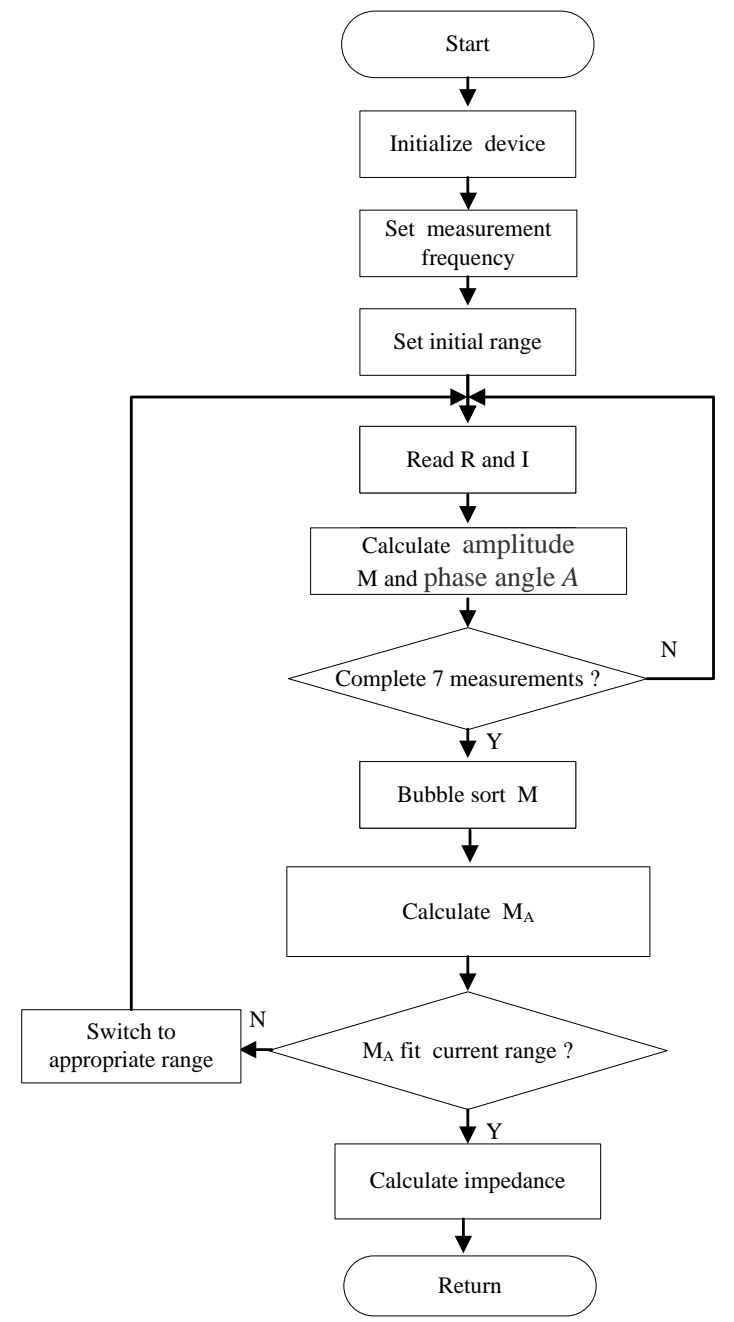

Fig. 3. Flow chart of impedance measurement subprogram

In the dialog box for data display and storage, the impedance amplitudes and phase angles measured before and after AI viruses were incubated with the anti-H5 antibodies immobilized on the surface of the electrode, the changes of impedance amplitudes and phase angles, and the testing results of positive or negative, were displayed and could be stored into a flash disk via USB port.

\section{Evaluation of Impedance Detector}

The impedance detector was evaluated using solid-state resistors, solid-state equivalent circuits of the electrode and AI virus. 


\subsection{Solid-state Resistor Evaluation}

Ten resistors with the accuracy of $1 \%$ ranging from $100 \Omega$ to $5 \mathrm{k} \Omega$ were respectively measured six times at the characteristic frequency of $100 \mathrm{~Hz}$. As shown in Fig.4, this impedance detector, compared to commercial E4980A precision LCR meter from Agilent, showed a relative error of less than $2.0 \%$ at the characteristic frequency of $100 \mathrm{~Hz}$ and a standard deviation of less than $2.5 \%$ in parallel tests.

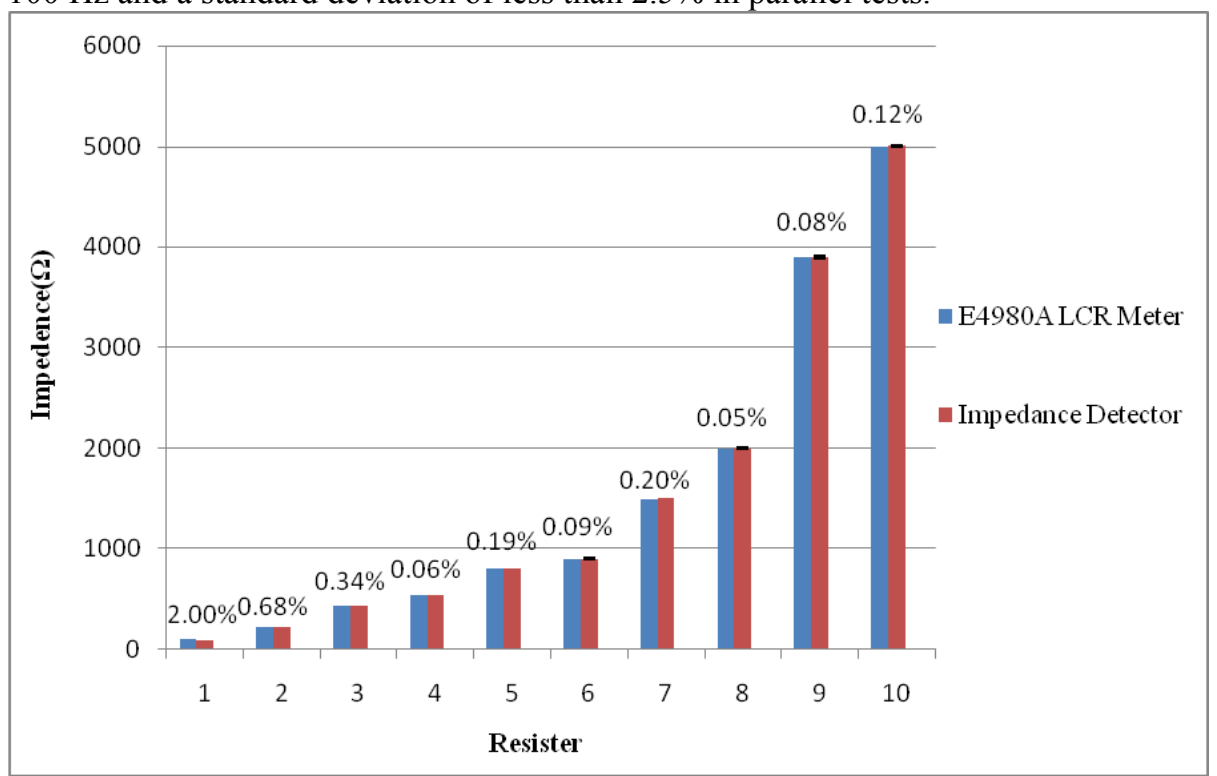

Fig.4. Comparison of impedance measurement of solid-state resistor at $100 \mathrm{~Hz}$ (Relative error $=\left|Z_{\text {Detector }}-Z_{\text {Meter }}\right| / Z_{\text {Meter }} * 100 \%$ )

\subsection{Equivalent Circuit Evaluation}

The impedance biosensor developed in our previous study could be simulated using Randle model shown in Fig. 5. The equivalent circuit included the electrolyte resistance $\left(R_{S}\right)$ representing the resistance of the bulk electrolyte solution, the electric double layer capacitor $\left(C_{d l}\right)$ representing the effect of ions near the surface of the electrode, and the electron transfer resistance $\left(R_{e t}\right)$ representing the resistance of the electron transfer of the redox probes .

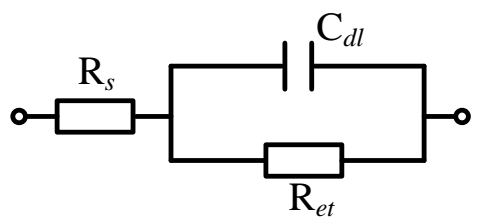

Fig.5. Equivalent circuit of the impedance biosensor

Four equivalent circuits consisted of solid-state resistors and capacitors with impedance amplitude ranging from $100 \Omega$ to $2 \mathrm{k} \Omega$ were respectively measured six 
times at the characteristic frequency of $100 \mathrm{~Hz}$. As shown in Fig.6, this impedance detector, compared to E4980A meter, showed a relative error of less than $1.0 \%$ at the characteristic frequency of $100 \mathrm{~Hz}$ and a standard deviation of less than $2.0 \%$ in parallel tests.

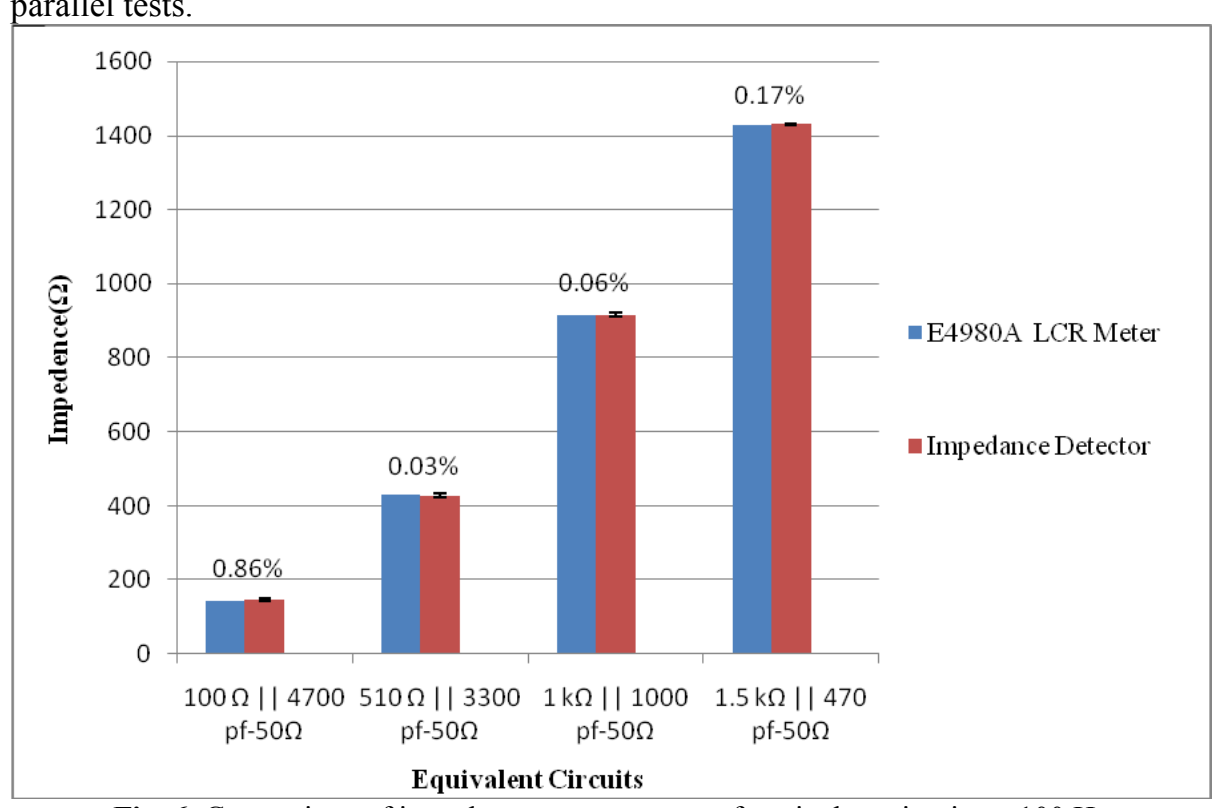

Fig. 6. Comparison of impedance measurement of equivalent circuits at $100 \mathrm{~Hz}$

\subsection{AI Virus Evaluation}

The evaluation by AI virus was conducted using IDA microelectrodes fabricated by wet-etching process in the Institute of Semiconductors, Chinese Academy of Sciences. The anti-H5 antibodies were immobilized onto the surface of the electrode by Protein A method [9-10] and impedance measurements of AI H5N1 virus with a concentration of $2^{4} \mathrm{HAU} / 50 \mu \mathrm{L}$ at $100 \mathrm{~Hz}$ were performed at the presence of $10 \mathrm{mM}$ $[\mathrm{Fe}(\mathrm{CN}) 6]^{3-4-}$ using E4980A meter and this developed impedance detector in parallel.

As shown in Fig.7, this impedance detector showed a relative error of less than 4.1\% at the characteristic frequency of $100 \mathrm{~Hz}$ and a standard deviation of less than $4.5 \%$ in parallel tests. 


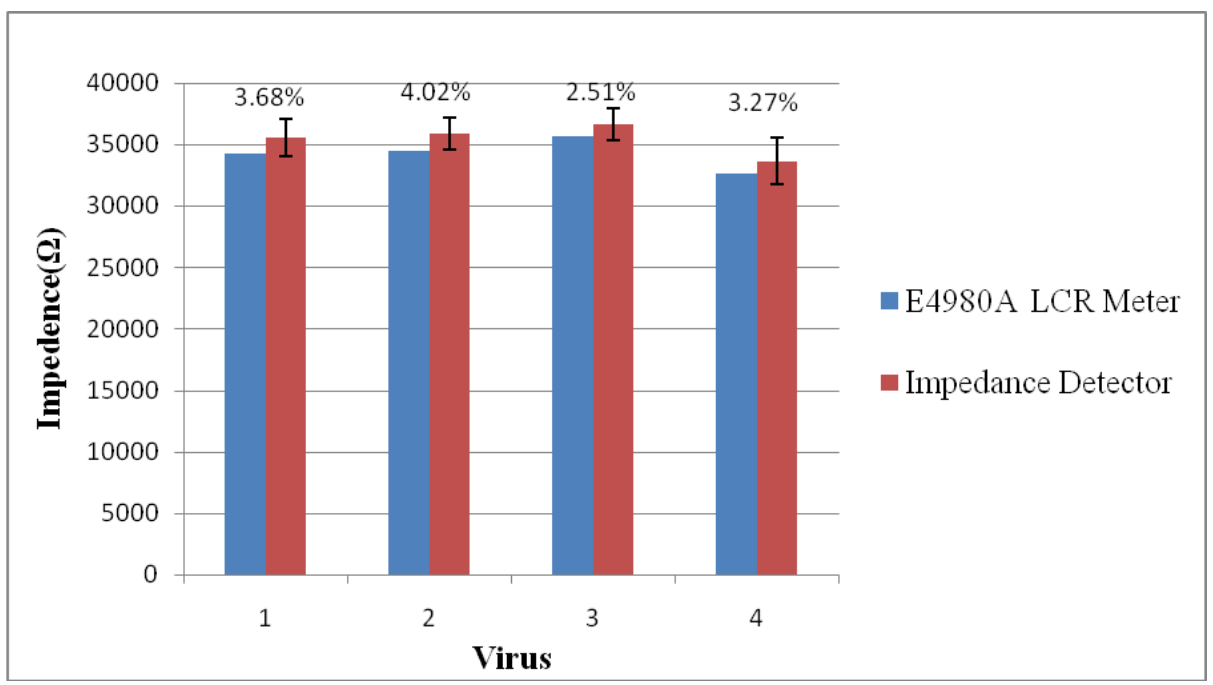

Fig.7. Comparison of impedance measurement of AI virus at $100 \mathrm{~Hz}$

This impedance detector was also used with the IDA microelectrodes modified by the anti-H5 antibodies to detect $\mathrm{AI} \mathrm{H} 5 \mathrm{~N} 1$ virus at the concentrations ranging from $2^{-1}$ to $2^{4} \mathrm{HAU} / 50 \mu \mathrm{L}$. As shown in Fig. 8, a linear relationship between impedance change $\triangle \mathrm{Z}$ and the concentration of $\mathrm{AI}$ virus was found and could be described as $\Delta \mathrm{Z}=70.28 \cdot \mathrm{C}+367.33\left(\mathrm{R}^{2}=0.92\right)$.

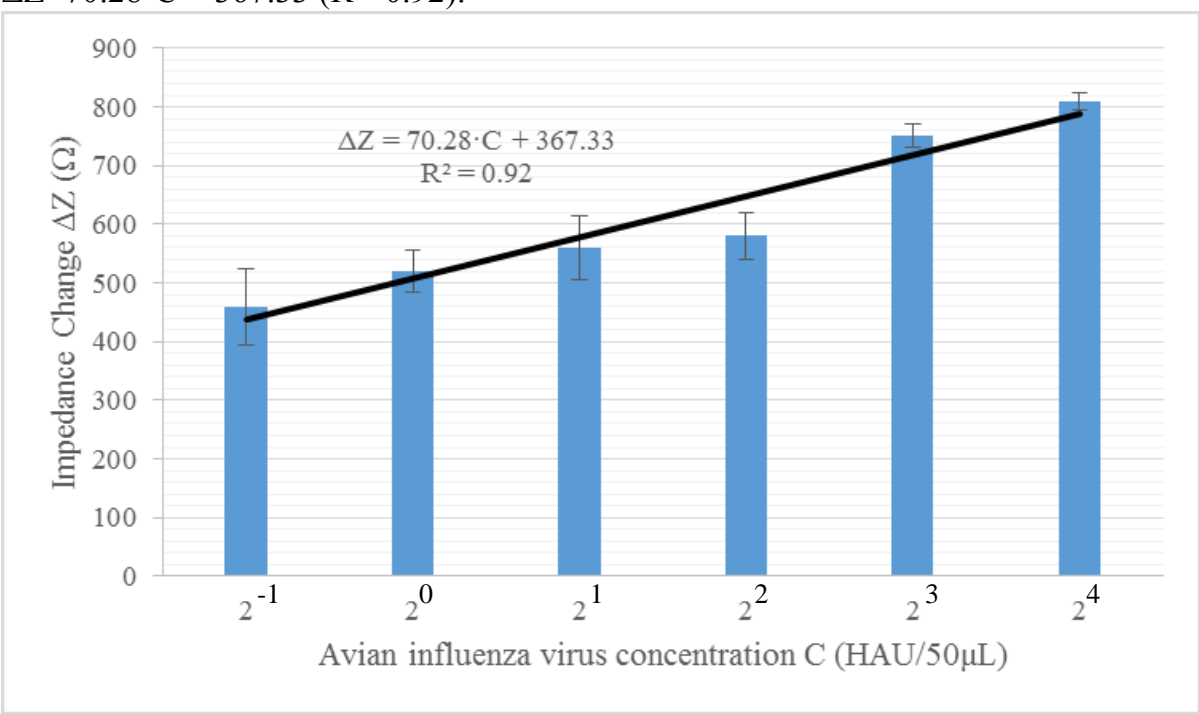

Fig. 8. Linear relationship between impedance change and AI virus concentration 


\section{Conclusions}

A portable impedance detector was redesigned and developed using an S3C2440AL ARM9 microprocessor and an improved AD5933 impedance converter with a comparable accuracy and stability in impedance measurements of both solid-state circuits and AI virus with commercial E4980A precision LCR meter, which could meet the requirements of the newly-redesigned IDA microelectrode for rapid detection of AI virus. This improved impedance detector is an important promotion of developing a simple, rapid, robust, cost-effective, and reliable detection method for in-field screening of avian influenza.

\section{Acknowledgment}

This study was supported by Special Fund for Agro-scientific Research in the Public Interest (No. 201303045), Chinese Universities Scientific Fund (No. 2014RC013) and Program of the Co-Construction with Beijing.

\section{References}

1. WHO, Human infection with avian influenza $\mathrm{A}(\mathrm{H} 5 \mathrm{~N} 1)$ virus - update, http://www.who.int/csr/don/2014_01_09_h5n1/, 2014

2. Miao Lu, Liu Zhongming, Zhang Shuihua. Research Evolvement of Electrochemical Immunosensor[J]. Chinese Journal of Medical Physics, 2006, 23(2):132-134.

3. Xiao Fei, Zhang Ningdan, Gu Hongjie, et al. A monoclonal antibody-based immunosensor for detection of Sudan I using electrochemical impedance spectroscopy [J]. Talanta, 2011, 84(1): 204-211.

4. Li Zaijun, Wang Zhongyun, Sun Xiulan, et al. A sensitive and highly stable electrochemical impedance immunosensor based on the formation of silica gel-ionic liquid biocompatible film on the glassy carbon electrode for the determination of aflatoxin $\mathrm{B}_{1}$ in bee pollen [J]. Talanta, 2010, 80(5): 1632-1637.

5. Geng Ping, Zhang Xinai, Meng Weiwei, et al. Self-assembled monolayers-based immunosensor for detection of Escherichia coli using electrochemical impedance spectroscopy[J]. Electrochimica Acta, 2008, 53(14): 4663-4668.

6. Li Dujuan, Wang Jianping, Gai Ling, Ying Yibin, et al. Rapid detection of Escherichia coli O157:H7 using electrochemical impedance immunosensor. Chinese Journal of Sensors and Actuators. 2008, 21(5):709-714.

7. Shi Hui, Sun Xiulan, Wang Hongxin, et al. Development of an Electrochemical Impedimetric Immunosensor for Determination of Microcystin-LR in Water [J]. Journal of Instrumental Analysis, 2009, 28(6): 633-637.

8. Sun Xiulan, Li Zaijun, Cai Yan, et al. Electrochemical impedance spectroscopy for analytical determination of paraquat in meconium samples using an immunosensor modified with fullerene, ferrocene and ionic liquid[J]. Electrochimica Acta, 2011, 56(3): $1117-1122$ 
9. Yan Xiaofei, Wang Ronghui, et al. Impedance Immunosensor Based on Interdigitated Array Microelectrodes for Rapid Detection of Avian Influenza Virus Subtype H5[J]. Sensor Letters, 2013, 11(6-7): 1256-1260.

10. Yan Xiaofei, Wang Maohua, Wen Xinhua, et al. Rapid detection of avian influenza virus using immunomagnetic separation and impedance measurement[J]. Applied Mechanics and Materials, 2013, 239: 367-371.

11. Ciszkowska M, Stojek Z. Graphite multi-micro-disc based mercury film electrode: Comparison of experimental and theoretical anodic stripping results[J]. Journal of electroanalytical chemistry and interfacial electrochemistry, 1985, 191(1): 101-110.

12. Cai Hong, Lee Thomas Ming-Hung, Hsing I-Ming. Label-free protein recognition using an aptamer-based impedance measurement assay[J]. Sensors and Actuators B: Chemical, 2006, 114(1): 433-437.

13. Kim Y. S., Niazi J. H., Gu M. B. Specific detection of oxytetracycline using DNA aptamer-immobilized interdigitated array electrode chip[J]. Analytica chimica acta, 2009, 634(2): 250-254.

14. Min J., Baeumner A. J. Characterization and optimization of interdigitated ultramicroelectrode arrays as electrochemical biosensor transducers[J]. Electroanalysis, 2004, 16(9): 724-729.

15. Ehret R., Baumann W., Brischwein M., et al. Monitoring of cellular behaviour by impedance measurements on interdigitated electrode structures[ $\mathrm{J}]$. Biosensors and Bioelectronics, 1997, 12(1): 29-41.

16. Chang B. W., Chen C. H., Ding S. J., et al. Impedimetric monitoring of cell attachment on interdigitated microelectrodes[J]. Sensors and Actuators B: Chemical, 2005, 105(2): 159163.

17. Berggren C., Bjarnason B., Johansson G. Capacitive biosensors[J]. Electroanalysis, 2001, 13(3): 173-180

18. Yang Liju, Li Yanbin, Erf G F. Interdigitated Array Microelectrode-Based Electrochemical Impedance Immunosensor for Detection of Escherichia coli O157: H7[J]. Analytical chemistry, 2004, 76(4): 1107-1113.

19. Yang Liju. Electrical impedance spectroscopy for detection of bacterial cells in suspensions using interdigitated microelectrodes[J]. Talanta, 2008, 74(5): 1621-1629.

20. Radke S. M., Alocilja E. C. A high density microelectrode array biosensor for detection of E. coli O157: H7[J]. Biosensors and Bioelectronics, 2005, 20(8): 1662-1667.

21. Valera E., Ramón-Azcón J., Rodríguez Á., et al. Impedimetric immunosensor for atrazine detection using interdigitated $\mu$-electrodes (ID $\mu$ E's) $[\mathrm{J}]$. Sensors and Actuators B: Chemical, 2007, 125(2): 526-537.

22. Wang Ronghui, Wang Yun, Lassiter K, et al. Interdigitated array microelectrode based impedance immunosensor for detection of avian influenza virus H5N1[J]. Talanta, 2009, 79(2): 159-164.

23. Wang R., Li Y., Mao X., et al. Magnetic bio-nanobeads and nanoelectrode based impedance biosensor for detection of avian influenza virus[C], Proceedings of IEEE Nano/Molecular Medicine and Engineering (NANOMED) 2010, 2010, 214-217.

24. Lin J., Lum J., Wang R., et al. A portable impedance biosensor instrument for rapid detection of avian influenza virus [C], Proceedings of IEEE SENSORS 2010, 2010, 15581563 